\title{
GRASSROOTS ECOLOGY: PLANT-MICROBE-SOIL INTERACTIONS AS DRIVERS OF PLANT COMMUNITY STRUCTURE AND DYNAMICS
}

\author{
Heather L. Reynolds, ${ }^{1}$ Alissa Packer, James D. Bever, and Keith Clay \\ Department of Biology, Indiana University, Bloomington, Indiana 47405 USA
}

\begin{abstract}
A growing body of research on plant-microbe interactions in soil is contributing to the development of a new, microbially based perspective on plant community ecology. Soil-dwelling microorganisms are diverse, and interactions with plants vary with respect to specificity, environmental heterogeneity, and fitness impact. Two microbial processes that may exert key influences on plant community structure and dynamics are microbial mediation of niche differentiation in resource use and feedback dynamics between the plant and soil community. The niche differentiation hypothesis is based on observations that soil nutrients occur in different chemical forms, that different enzymes are required for plant access to these nutrients, and that soil microorganisms are a major source of these enzymes. We predict that plant nutrient partitioning arises from differential associations of plant species with microbes able to access different nutrient pools. Feedback dynamics result from changes in the soil community generated by the specificity of response in plantmicrobe interactions. We suggest that positive feedback between plants and soil microbes plays a central role in early successional communities, while negative feedback contributes both to species replacements and to diversification in later successional communities. We further suggest that plant-microbe interactions in the soil are an important organizing force for large-scale spatial gradients in species richness. The relative balance of positive feedback (a homogenizing force) and negative feedback (a diversifying force) may contribute to observed latitudinal (and altitudinal) diversity patterns. Empirical tests of these ideas are needed, but a microbially based perspective for plant ecology promises to contribute to our understanding of long-standing issues in ecology, and to reveal new areas of future research.

Key words: diversity; mycorrhizal fungi; $N$-fixing bacteria; niche partitioning; plant ecology; soilborne pathogens; succession.
\end{abstract}

\section{INTRODUCTION}

Ecological theory recognizes a variety of abiotic and biotic factors that shape the structure and dynamics of terrestrial plant communities. Climate, age, environmental harshness, area, isolation, disturbance, environmental heterogeneity, and biotic interactions may all play key roles in determining plant community composition and diversity in space and time (Tilman and Pacala 1993, Rosenzweig 1995). Much of plant ecological theory has been dominated by debate over the relative importance of these factors, manifest in controversy over plant strategy theory and the relationships between competition intensity, species diversity, and habitat productivity (Reynolds 1999, Aarssen 2001). Among the biological forces structuring plant communities, plant-microbe interactions have received little attention (Thompson et al. 2001). This is not surprising, given the overwhelming diversity of soil microbes (Torsvik et al. 1994), the technical challenges involved in their study, the tendency to view microbial associates as simply extensions of the plant and their outright exclusion from experimental designs through

Manuscript received 15 May 2002; revised 26 August 2002; accepted 11 September 2002. Corresponding Editor: A. A. Agrawal. For reprints of this Special Feature, see footnote 1, p. 2256

${ }^{1}$ E-mail: hreynold@ bio.indiana.edu use of artificial soil mixes or soil amendments that result in depleted microbial communities.

In recent years, however, a growing body of ecological research on plant-microbe interactions in soil has developed. A new, microbially based perspective on plant community structure and dynamics is emerging from this work. In this paper, we review the diversity of plant-microbe interactions in soil and discuss the costs and benefits to each partner. We discuss the role of environmental heterogeneity and host specificity in generating a continuum of positive and negative effects, both direct and indirect. Two processes, mediation of niche differentiation in plant resource use and feedback dynamics between the plant and soil community, emerge from these fundamentals as key microbial influences on plant community structure and dynamics. We discuss the evidence for these processes and their applications to understanding temporal and spatial vegetation patterns. We conclude with a look toward how a microbial perspective can inform future research directions in plant ecology.

\section{Basics of Plant-Microbe Interactions}

\section{Diversity and function}

Soil-dwelling microorganisms encompass a diversity of phylogenetic groups and all three major functional

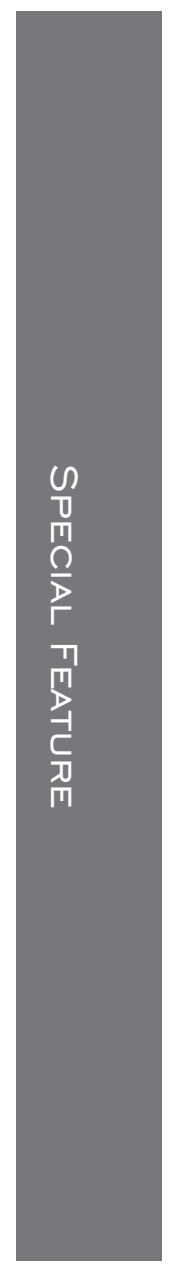


groups (producer, consumer, and decomposer). Genetic diversity can be exceptional-several thousand genomes per gram of soil (Torsvik et al. 1990). Yet our knowledge of microbial species diversity is still in its infancy (Tate 1997). Interactions between soil microbes and plants span the range from mutualistic to pathogenic. As decomposers, soil microbes are indirectly responsible for the bulk of terrestrial vegetation's annual nutrient demand (Schlesinger 1991). In turn, plant matter is the major source of photosynthetically fixed carbon for decomposers. Yet microbes and plants also compete for soil nutrients (Hodge et al. 2000a), making their relationship simultaneously mutualistic and competitive (Harte and Kinzig 1993). In contrast, nitrogenfixing bacteria and mycorrhizal fungi enhance host plant fitness by direct provisioning of mineral resources or by providing protection against other pests. Nonmycorrhizal fungi, various rhizosphere bacteria, protozoa, and nematodes have also been shown to protect plants from soilborne enemies like fungi, bacteria, actinobacteria, protozoa, nematodes, and viruses (Lavelle and Spain 2001). Such pathogens are responsible for damping-off diseases, vascular wilts, and root rots (Ka$\tan$ 1991).

\section{Continuum of effects: environmental dependence}

Many of the effects of microbes on plants are dependent upon environmental conditions. For example, the benefits that plants receive from nutritional mutualisms with soil microbes (e.g., nitrogen-fixing bacteria and mycorrhizal fungi) depend upon the availability of essential soil minerals. Available phosphorus (P) is often the primary determinant of plant dependence on arbuscular mycorrhizal (AM) fungi, such that the effect of the interaction can be negative under high $\mathrm{P}$ conditions (Bethlenfalvay et al. 1982). The benefit that plants receive from protective mutualisms is also environment dependent, as the benefit depends upon the presence of enemies. A similar environmental dependence is inherent in the interactions of plants and soil pathogens. Major groups of soil pathogens (e.g., Pythium) have high pathogenesis under a limited range of environmental conditions (e.g., wet and warm). The ability of plants to tolerate or ward off pathogens is also dependent upon environmental factors such as nutrient and light availability. Thus, the impact of soil communities on plant community processes will also be a function of environmental factors, presenting a particular challenge to investigations of the community consequences of plant-soil-microbe interactions.

\section{Specificity of association vs. specificity of response}

Mutualistic and pathogenic associations between plants and soil microbes are known to range in their specificity from highly specific associations between orchids and their mycorrhizal fungal symbionts to the cosmopolitan associations of plant roots with rhizosphere bacteria. It is useful to distinguish the specificity of association (i.e., the ability to form specific associations) and the specificity of the plant and microbe responses to their association (i.e., the dependence of relative fitness on specific associations, as estimated by specificity of growth responses). While these two aspects of specificity are not completely independent, they are not necessarily collinear either. For example, interactions that have relatively high specificity of association, such as the association between ectomycorrhizal host plants and ectomycorrhizal fungi, might also be expected to show relatively high specificity of response. However, this does not imply that plant-microbe interactions that show low specificity of association also show low specificity of response. The interaction of plants and AM fungi shows relatively low specificity of association, but the response of plants to individual species of AM fungi can vary greatly depending on the plant-AM fungal combination (Van der Heijden et al. 1998). Similarly, the relative growth rates of AM fungi also depend greatly on the identity of the plant with which they are associated (Eom et al. 2000; Bever 2002). Specificity of infection and of plant response is also a well-known characteristic of soil pathogens (Bruehl 1987, Agrios 1997). In fact, when measured, soil microbes commonly show specificity of response to plant species and specificity of growth effects on those hosts. While the specificity of association is important for establishing the potential relationships, the specificity of response determines the community dynamics resulting from these associations (Bever 1999).

\section{Microbial Mechanisms for the Maintenance OF DIVERSITY}

Given a local species pool, the species diversity of a given area depends on the existence of mechanisms that prevent a competitive dominant from excluding all other species. Recognizing that competition occurs over resources, coexistence mechanisms may be categorized on the basis of whether (Aarssen 1984) (1) competition is avoided in the first place, through resource partitioning (e.g., rooting depth differences), or (2) competitive exclusion is avoided, despite overlap in resource use (e.g., competitive reversal). Here, we discuss new facets to these coexistence mechanisms that emerge from a microbially based perspective.

\section{Microbial mediation of resource partitioning}

We focus here on soil nitrogen (N) and P, the two most common limiting nutrients in terrestrial ecosystems (Chapin et al. 1986). These nutrients exist in a variety of inorganic (e.g., ammonium, phosphate) and organic (e.g., amino acids, nucleic acids) pools made available to plants through the action of soil enzymes (e.g., proteases, ribonucleases), the bulk of which are thought to come from bacteria and fungi (Tabatabai and Dick 2002). If microbes or their enzymatic activities are differentially associated with plant species, a 


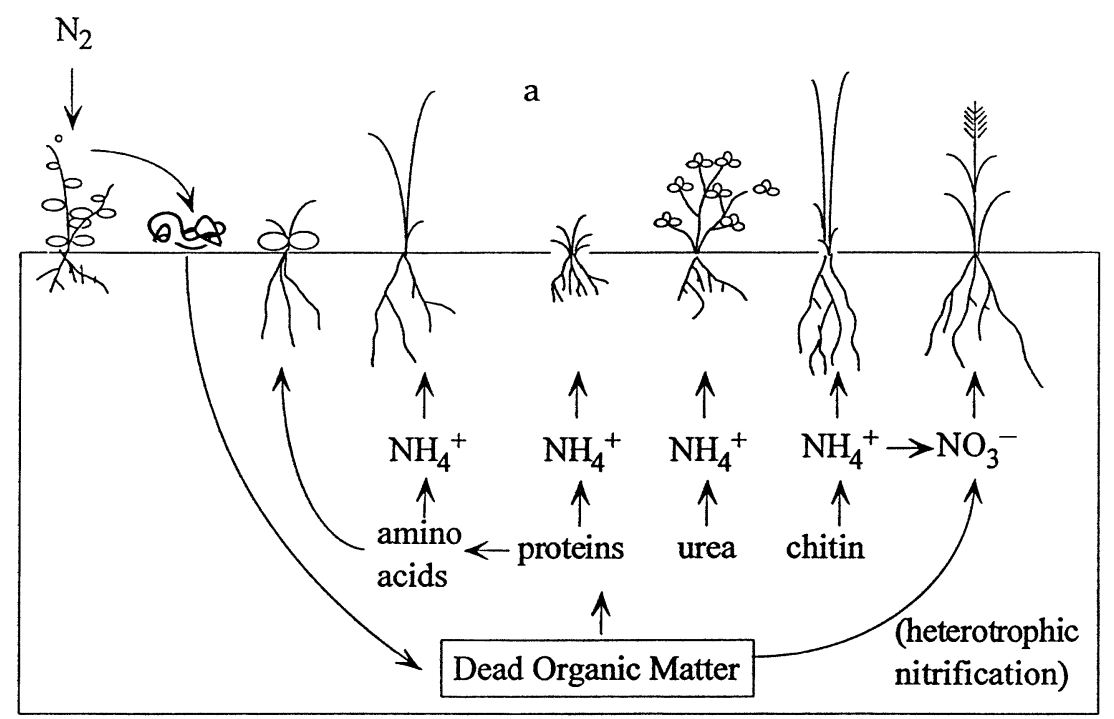

b

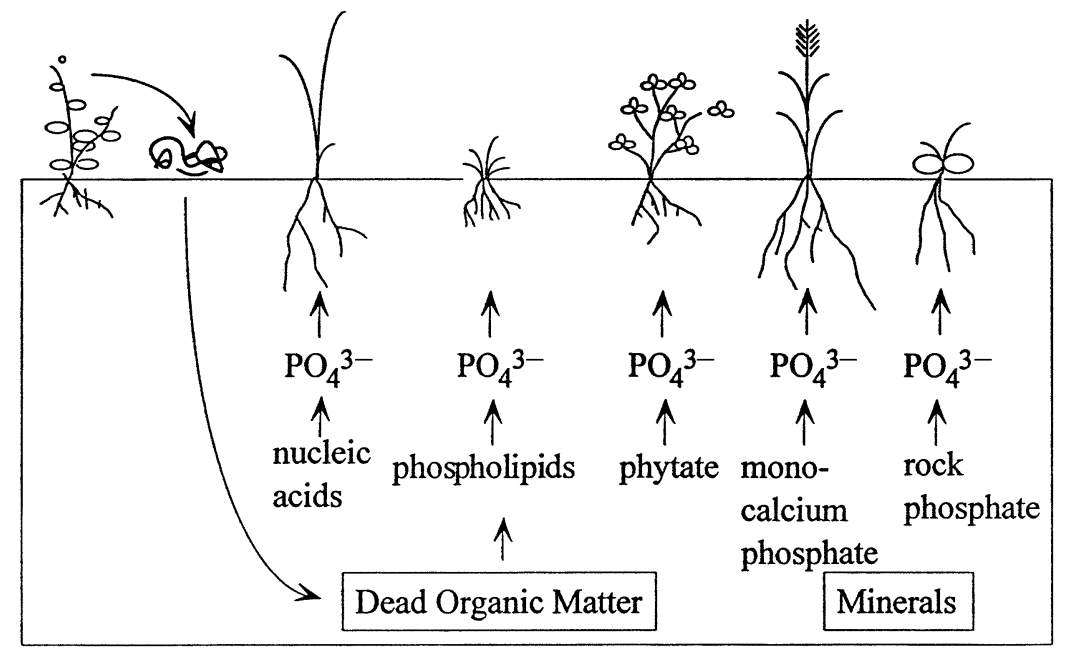

FIG. 1. (a) $\mathrm{N}$ partitioning. Different plant species access different forms (e.g., $\mathrm{NO}_{3}{ }^{-}$vs. $\mathrm{NH}_{4}{ }^{+}$vs. amino acids) or sources (e.g., $\mathrm{NH}_{4}{ }^{+}$from $\mathrm{N}_{2}$, proteins, urea or chitin) of $\mathrm{N}$. (b) A similar model can be envisioned for $\mathrm{P}$ nutrition.

kind of resource partitioning may arise in which different plant species access different pools, thus avoiding competition for the same pools (Fig. 1). In this way, plants may experience a single nutrient axis (e.g., $\mathrm{N})$, as a diversity of axes, thereby vastly increasing the number of niches available for competing plant species. On the surface, this is simply the standard niche-partitioning model, but the niche partitioning is enabled by soil microbes.

Under the simplest form of the microbial mediation hypothesis, a single microorganism is able to produce the entire range of enzymes and different plant species cause this "super microbe" to express different enzymes. However, inevitable physiological trade-offs and the diversity of microorganisms with distinct enzymatic capabilities make this super microbe hypothesis untenable. A more realistic hypothesis is that plant species associate with different groups of microbes, so gaining differential access to nutrient pools. Confirmation of this hypothesis would have the important implication that plant species coexistence depends upon soil microbial diversity and microbial dynamics.

Evidence for microbially mediated resource partitioning.-Evidence for less obvious forms of microbially mediated nutrient partitioning than that between plants with $\mathrm{N}$-fixing symbionts and plants that rely on soil $\mathrm{N}$ awaits future studies. Evidence for partitioning of plant species into ammonium, nitrate, and amino acid specialists is accumulating in a range of ecosystems (McKane et al. 2002, Miller and Bowman 2002), although a specific role for microbes has not been established. Nor do we know whether plant species, via microbial associations, differentially access complex organic pools, such as protein, chitin, or nucleic acids. 
We do know that microbial populations are highly elevated in the rhizospheres surrounding plant roots (Paul and Clark 1996), where they may be influenced by the quality and quantity of substances that plant roots continuously exude (Rovira 1969, Hamilton and Frank 2001). Thus, the possibility arises that specific plant-microbe and/or plant-microbial-enzyme associations could develop. Differential plant-microbe associations have been observed (Grayston et al. 1998, Westover and Bever 2001). Yet, with the obvious exception of $\mathrm{N}$ fixation, the potential relevance of such associations for plant $\mathrm{N}$ and $\mathrm{P}$ partitioning has not been investigated.

Mycorrhizal mediation of resource partitioning.Mycorrhizae are potentially key players in this model of microbially mediated $\mathrm{N}$ and $\mathrm{P}$ partitioning. All forms of mycorrhizal fungi exhibit phosphatase activity (Marschner 1995). In otherwise sterile soil, AM grasses showed increased growth and $\mathrm{P}$ uptake compared to noninfected plants when supplied with such organic $\mathrm{P}$ sources as ribonucleic acid (RNA) (Jayachandran et al. 1992) and phytate (Jayachandran et al. 1992, Tarafdar and Marschner 1994). Ecto- and ericoid mycorrhizae are capable of breaking down complex organic $\mathrm{N}$ and taking up dissolved organic $\mathrm{N}$ such as amino acids (Ahmad and Hellebust 1991), allowing plants direct access to organic N (Turnbull et al. 1995, 1996). A number of studies have now also demonstrated enhanced acquisition of inorganic and organic $\mathrm{N}$ sources by AM plants (Michelsen et al. 1996, Hawkins et al. 2000). A key issue is whether, like ecto- and ericoid mycorrhizae, AM fungi are able to directly access complex organic $\mathrm{N}$ forms (e.g., chitin) or whether they simply enhance the ability of plants to compete with free-living heterotrophic microbes for the products of organic matter mineralization. Recent studies have been conflicting (Hodge et al. 2000b, 2001).

Might mycorrhizae facilitate differential access of plant species to different pools of $\mathrm{N}$ and P? Prior research with AM fungi has focused almost exclusively on a few AM fungal species in a single genus (Glomus). Yet substantial host specificity of AM fungi with plant hosts has been demonstrated (Bever et al. 1996, Van der Heijden et al. 1998). This host specificity, in combination with AM fungal diversity, has been implicated in the maintenance of plant community diversity (Van der Heijden et al. 1998, Bever et al. 2001), although the specific mechanism is not known. The potential for microbially mediated niche partitioning may be even greater in ecto- and ericoid mycorrhizae, which are thought to be more diverse than AM fungi and to exhibit greater host specificity. For example, isolates of four ectomycorrhizal species from northern Australian forests had different abilities to use a range of amino acids, protein and inorganic $\mathrm{N}$ sources and this was affected by host plant identity (Turnbull et al. 1995). More studies of this sort are needed for mycorrhizae in general.

\section{Positive vs. negative feedback dynamics}

A second, qualitatively distinct manner in which interactions with soil microbes can contribute to the maintenance of diversity in plant communities is through feedbacks on plant growth resulting from changes in the composition of the soil community. While feedbacks may be involved in microbially mediated resource partitioning, we focus here on feedback dynamics involving plants with overlapping resource use. Feedbacks result from the community dynamics generated by the specificity of response in plant-microbe interactions. Because growth rates of microbes are known to be host dependent, the composition of the soil community will likely change due to the identity of the local host plant. Moreover, as the growth promotion of soil microbes is also host-specific, the change in the composition of the soil microbes will likely alter the relative performance and local abundance of different plant species. The feedback then represents the dynamics of the net direct effects of the microbial community on individual plant types.

Expected dynamics of feedback.-The growth consequences of soil community feedback can be positive or negative. For example, if the presence of plant species A causes an accumulation of microbes that specifically benefit that host, then the relative performance of plant A with its soil community will improve over time. This positive feedback dynamic will be expected to reinforce the initial abundance of plant A and lead to the loss of other plant types from the local community, at least on a local scale (Bever et al. 1997, Bever 1999).

In the case of negative feedback, a given host performs relatively worse with its own soil community over time. This can result from host-specific degradation of the soil community, such as might result from the accumulation of species-specific pathogens. However, negative feedback can also result from host-specific changes in the composition of the soil community that improve the growth of a second plant species (i.e., an indirect facilitation mediated by the change in the microbial community). The composition of the mycorrhizal fungal community, for example, might change in a manner that improves the growth of a competing plant species (Bever 1999, 2002). Negative feedback will prevent any single plant species from dominating a site and thereby contribute to the coexistence of competing plant species (Bever et al. 1997).

Evidence for positive feedback.-Positive feedback is known to play an important role in plant-soil community interactions. Positive feedback dynamics are evident in the limited success of plant establishment in the absence of particular symbionts, as illustrated by the history of pine forests in the tropics. Attempts at growing pine failed until trees were inoculated with compatible ectomycorrhizal fungi, and now these pines are increasingly perceived as a potentially invasive spe- 
cies (Rejmanek and Richardson 1996). A similar pattern has been found with invasive Russian olive (Elaeagnus angustifolia) and its N-fixing Frankia symbiont (Richardson et al. 2000). Similarly, the success of plants that are dependent upon AM fungi or N-fixing bacteria are dependent upon the initial abundance of their symbionts (Medve 1984, Larson and Siemann 1998). Local-scale positive feedback is expected to maintain sharp boundaries between patches (Molofsky et al. 2001), and contribute to the maintenance of boundaries between vegetation dominated by plants associated with arbuscular vs. ectomycorrhizal fungi.

Evidence for negative feedback.-There is accumulating evidence of negative feedback's important role in structuring plant communities. In agricultural settings, the accumulation of species-specific soil pathogens drives the rotation of crops. Much of the evidence for negative feedback in unmanaged communities has come from efforts to test the Janzen-Connell hypothesis that high tropical forest tree diversity results from negative density-dependent mortality resulting from species-specific seed predation or herbivory (Janzen 1970, Connell 1971). Seedling mortality in tropical forests has been repeatedly found to increase with the density of conspecifics (e.g., Wills et al. 1997, Harms et al. 2000) and with proximity to mature conspecifics (Augspurger 1992, Condit et al. 1994). Current evidence suggests accumulation of soilborne pathogens as the causal mechanism for these effects (Augspurger and Kelly 1984, Augspurger 1988). In temperate forests of eastern North America, negative feedbacks may drive the reciprocal replacement and coexistence of beech and maple codominants (Fox 1977, Woods 1979), although the soil microbial mechanism has not been demonstrated. The high mortality of black cherry (Prunus serotina) seedlings near adult conspecifics and at high seedling densities has been shown to result from accumulation of soil pathogens in the genus Pythium (Packer and Clay 2000).

There is also accumulating evidence of negative soil community feedbacks playing an important role in grassland communities. In greenhouse assays of soil community feedback within an old field community in North Carolina, negative feedback was found in nine of the 14 pairwise comparisons tested (Bever 1994, Bever et al. 1997). In this system, several complementary microbial mechanisms of negative feedback have been identified, including the accumulation of hostspecific soil pathogens in the genus Pythium (Mills and Bever 1998, Westover and Bever 2001), host-specific shifts in the composition of rhizosphere bacteria (Westover and Bever 2001), and host-specific changes in the composition of the AM fungal community (Bever 2002). Negative feedbacks have also been found to drive plant community dynamics within sand dune communities (Van der Putten et al. 1993). Again, complementary microbial mechanisms have been identified, with accumulation of root feeding nematodes working synergistically with pathogenic fungi to decrease plant growth (Van der Putten et al. 1990, Van der Putten and Troelstra 1990). Soil communities have also been suggested as a driver of plant community dynamics in tallgrass prairies (Holah and Alexander 1999) and European grazed grasslands (Olff et al. 2000). In the latter system, the negative soil community feedbacks have been implicated as a cause of a shifting mosaic of grassland dominants (Olff et al. 2000), a pattern predicted by spatial simulations of this process (Molofsky et al. 2002).

\section{LARge-SCAle Vegetation Patterns}

In the previous section, we discussed how microbially mediated resource differentiation and feedback have implications for the maintenance of plant community diversity at a local scale. Here, we discuss how these processes may contribute to large-scale vegetation patterns. We hypothesize that the relative importance of positive versus negative feedback processes shifts over temporal and spatial gradients, with positive feedback processes dominating earlier in succession and at high latitudes and altitudes and negative feedback processes dominating later in succession and at low latitudes and altitudes. This hypothesis could be tested in natural communities by examining plant-soil feedback over successional and spatial gradients.

\section{Temporal patterns}

Vegetation change over time, or succession, is characterized by sequential species replacements, typically accompanied by changes in community diversity. Classic successional models focus on vegetation-based mechanisms of species replacement, differing in emphasis on recruitment limitation, life history strategy, environmental modification, and competitive exclusion (Connell and Slatyer 1977, Tilman 1988). The role of plant-microbe interactions in such models is principally limited to that of $\mathrm{N}$-fixing associations in facilitation. Yet evidence for microbial influences on succession can be found in early work, which established that many soil microbes vary predictably with vegetation through succession (Tresner et al. 1954, Wohlrab et al. 1963). More recently, mycorrhizae (Janos 1980, Read 1991) and soil pathogens (Van der Putten et al. 1993, Clay and Van der Putten 1999) have been recognized as potentially important drivers of succession. Here, we consider plant-microbe interactions in species replacements and changes in community diversity through succession, using the context of feedback and resource differentiation.

\section{Species replacements}

Positive feedback.-Soil mutualists and pathogens can be limiting in the very beginning stages of both primary and secondary successions, favoring asymbiotic, ruderal, life history strategies (Janos 1980, Sprent 1993), particularly in secondary successions, 


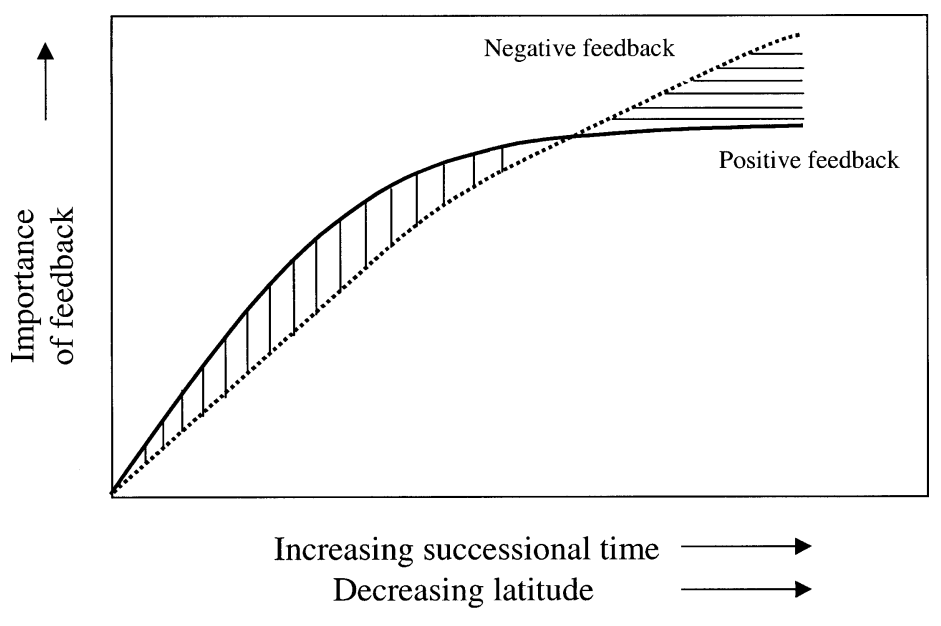

FIG. 2. A conceptual model of how the relative strength of positive and negative feedback changes over successional time and over latitudinal gradients. The exact shape of the curves does not matter. The important point is that there is a switchover point at some intermediate successional time or latitude where the strength of negative feedback exceeds that of positive feedback. where soil nutrient availability is comparatively higher. As mutualists and their plant hosts arrive at a site, positive feedback dynamics cause populations of both to build (Fig. 2).

The importance of positive feedback dynamics between plants and $\mathrm{N}$-fixing microbes in primary successions is well recognized. In the classic example of primary succession at Glacier Bay, N-fixers such as Dryas are among the first vascular plants to colonize (Crocker and Major 1955). Similar dynamics are expected between host plants and mycorrhizal fungi. Janos (1980) envisioned a shift from nonmycorrhizal to obligately mycorrhizal plants from early to late secondary succession, with low levels of facultatively mycorrhizal associations throughout. In sand dune and many other successional communities there is also a shift later in succession from herbaceous plant species involved in obligate symbioses with AM fungi to woody species involved in obligate symbioses with ecto- or ericoid mycorrhizae (Smith and Read 1997), coincident with a shift in predominance of inorganic versus organic N (Read 1993).

In the case of $\mathrm{N}$-fixing species, death and decomposition of $\mathrm{N}$-fixing species results in soil building over time. Thus, the benefits of $\mathrm{N}$-fixation are not restricted to the plant host (Chapin et al. 1994), and a positive feedback dynamic transitions to facilitation of additional plant species. $\mathrm{N}$-fixing associations may play a similar role in secondary successions on infertile soil. In contrast to $\mathrm{N}$-fixing associations, mycorrhizal associations are relatively ubiquitous and act to increase access to rather than add nutrients to soil. The availability of $\mathrm{P}$ and other nutrients often decrease in late succession (Walker and Syers 1976). The expectation might therefore be of a strong role for mycorrhizae throughout much of succession, after an initial recruitment-limited (and total N-limited, for primary succession) phase.

Negative feedback.-Negative feedback dynamics are expected to be less important during the initial stage of succession, which is characterized by harsher conditions and lower host densities than are favorable to most disease organisms. As plant host densities build and modify the abiotic environment, conditions should become more favorable to soil pathogens, leading to an increasing role for negative feedback in driving species replacements in succession (Fig. 2). Van der Putten et al. (1993) showed that soilborne diseases can drive successional change in a foredune community; individuals showed reduced biomass in the soil of their successors, but not in the soil of their predecessors. The traits of early successional species themselves may make them particularly vulnerable to negative feedback by soil pathogens. Rapid growth is a well-known trait of ruderal species, and it is also established that rapid growth trades off with allocation to herbivore defense (Coley et al. 1985, Poorter 1990). Given the assumption that belowground patterns of growth and defense mirror aboveground patterns, ruderal species, by their own success, increase the likelihood that they will be replaced by slower growing species, better defended against pathogens. Early and late successional species differ in quality as well as quantity of antiherbivore defense; defenses of ruderals tend to be against generalist herbivores while defenses of climax species tend to be against specialists (Coley et al. 1985). Extrapolating belowground once again, this suggests that specialization of plant defenses against soil pathogens will increase over successional time.

Microbially mediated resource differentiation.- Microbially mediated resource partitioning might play a role in species replacements if the forms of $\mathrm{N}$ or $\mathrm{P}$ change through succession. Gorham et al. (1979) implicated fungal symbionts in such sequential partitioning. Indeed, the example given above, of a shift from arbuscular to ecto- or ericoid mycorrhizal plant species with a change in inorganic to organic forms of $\mathrm{N}$ is an illustration of this process. Other shifts in forms of nutrients over succession (e.g., nitrate to ammonium, or protein to chitin) would provide the opportunity for 
additional species replacements on the basis of soil resource specialization.

\section{Community diversity}

Feedback.-Positive feedback, operating alone, would be expected to lead to monocultures, or even, in the absence of soil building or temporal shifts in forms of nutrients (e.g., inorganic to organic N), arrested successions. It has been suggested, for example, that higher host specificity of ecto- compared to endomycorrhizae leads to dominance by ectomycorrhizal species, to the exclusion of endomycorrhizal species (Connell and Lowman 1989). Even mycorrhizal networks (where benefits are shared by many hosts) can lead to lower diversity if one species in the network is the dominant sink for nutrients (Connell and Lowman 1989, Allen and Allen 1990). In contrast, the process of negative feedback through the soil community can generate a pattern of increased species diversity over successional time. Plant life histories and pathogen colonization opportunities vary with succession and offer two explanations for the increases in plant diversity during early succession. As soil pathogens remove weakly defended plants, only better defended plants remain. Later successional species with greater investment in defense are less susceptible to generalist pathogens and only vulnerable to attack by more specialized pathogens that are able to overcome their more sophisticated plant defenses. Increased specialization of pathogens should lead to reciprocal negative feedback that promotes plant species coexistence. Furthermore, opportunities for pathogen dispersal to a site increase over succession, leading to greater pathogen diversity and increasing the chances for reciprocal negative feedback.

Microbially mediated resource differentiation.Community complexity increases during succession as plant, microbial, and animal species diversity increase, and this leads to increases in the quantity and kinds of nutrient pools. This is expected to be particularly true for primary succession, but could also operate to a lesser extent in certain kinds of secondary succession, such as those initiating after severe fire, where much of the above- and belowground resources may be volatilized and homogenized. We suggest that as the diversity of microbes and nutrient inputs increase over succession, the opportunity for microbially mediated differentation in resource use increases, promoting increased plant community diversity over succession. Supporting this idea, ectomycorrhizal infectiveness and diversity has been found to increase over a successional gradient (Boerner et al. 1996).

Microbe-mediated niche diversification will also be affected by the specificity of the associations between plants and microbes. In the case of soil pathogens and mycorrhizal fungi, associations typically exhibit higher levels of specificity as succession proceeds. If the same pattern is true for the microorganisms involved in me- diating resource differentiation, then we would predict greater opportunities for species coexistence (i.e., greater specialization of resource niches) as succession proceeds.

\section{Spatial Patterns}

Large-scale spatial patterns in the organization and diversity of ecological communities are well known, and the underlying causes are much debated (Rosenzweig 1995). Species diversity, primary productivity, and environmental equitability all tend to increase with decreasing latitude (or altitude), corresponding to increasing mean temperature and precipitation (Waide et al. 1999, Mittelbach et al. 2001). Correlated changes in multiple environmental variables make the underlying mechanisms difficult to assign, but a variety of abiotic and biotic factors have been proposed as key drivers (Waide et al. 1999). We suggest that plantmicrobe interactions in the soil, particularly feedback processes, may also be an important driver of largescale spatial gradients. We predict that the relative balance of positive and negative feedback shifts towards negative feedback as productivity increases with decreasing latitude or altitude (Fig. 2). Relatively few empirical studies have attempted to assess the relative strength of positive and negative feedback in the soil over large-scale spatial gradients but there is a rich conceptual and theoretical literature. Further, results from a number of studies indirectly contribute to our understanding of microbial interactions with plants over large spatial scales.

\section{Mutualism and positive feedback}

Positive interactions may be particularly advantageous in extreme environments, such as those at high latitude or altitude (Sanders 1968), and facilitation has been associated with habitats of high abiotic stress (Greenlee and Callaway 1996, Choler et al. 2001). Adaptations to physical stresses often arise from mutualistic symbioses with microbes, and these symbioses are often characterized by the host-specificity required to generate positive feedback. It has been hypothesized that as terrestrial productivity increases and light becomes increasingly limiting, the high energetic costs of $\mathrm{N}$ fixation may outweigh its benefits (Gutschick 1981). If this is generally true of mutualistic symbioses with microbes (at least those requiring significant carbon inputs from the plant host) then it would promote a gradient of increasing importance of positive feedback between plants and soil microbes with increasing latitude or altitude (and decreasing primary productivity).

\section{Pest pressure and negative feedback}

Insofar as latitude and altitude are surrogates for temperature and precipitation, pest and pathogen pressure should increase as productivity increases with decreasing latitude or altitude (Weltzien 1972, Givnish 1999).

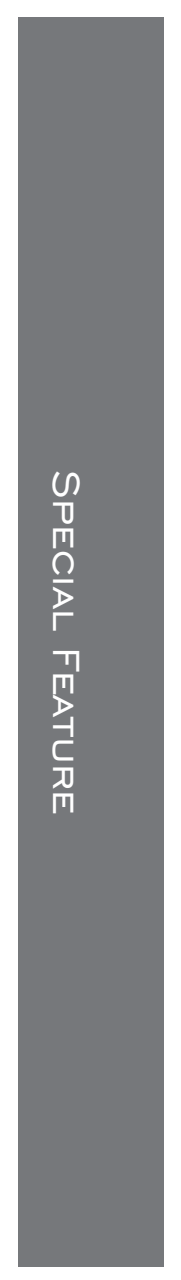


For example, damping-off fungi, which are major sources of seedling mortality for tropical tree species (Augspurger and Kelly 1984), thrive in warm, moist habitats. Levin (1975) concluded, based on a review of much evidence, that pathogen pressure is greater in the tropics.

Additional evidence for a latitudinal gradient in pathogen pressure comes from agriculture. It is well established that plant species diversity, which generally decreases with latitude, may reduce the incidence and severity of disease (Elton 1958, Knops et al. 1999), but, when diversity is held constant, a latitudinal effect is evident. For example, disease diversity of soybean, the United States' second largest cash crop and grown over a wide latitudinal range, was shown to be significantly correlated with latitude, with the largest number of soybean diseases occurring further south (Yang and Feng 2001). On a worldwide basis Septoria tritici blotch of wheat decreased linearly with increasing distance from the equator, although $S$. nodorum blotch increased with increasing latitude (Leath et al. 1993).

In order to lead to diversity-maintaining negative feedback, pest pressure must operate in a host-specific way. There is evidence that soil pathogens generate negative feedback in the tropics (Augspurger 1988). Consistent with the mechanism of negative feedback, density-dependence in the survival and growth of many tropical tree species has also been reported (Wills et al. 1997, Harms et al. 2000), although a recent study found that similar proportions of tree species are affected by density-dependent mortality in temperate vs. tropical forests (HilleRisLambers et al. 2002).

The correlation between latitude and outbreeding reproductive systems lends further support to the idea that negative feedback is greater at lower latitudes. Sexual reproduction is a mechanism by which host populations can generate and regenerate rare host genotypes favored in the face of pathogen attack (Clay and Kover 1996). Plants in tropical regions are more frequently characterized by outbreeding mechanisms than plants in temperate areas, and increased pest pressure in tropical systems may be responsible for this pattern (Levin 1975). Results from animal systems also support this conclusion (Ghiselin 1974, Glesener and Tilman 1978).

\section{The case for feedback}

Positive feedback is certainly not limited to stressful habitats, nor is negative feedback limited to the tropics. For example, ectomycorrhizal seedlings strongly benefit from proximity to parent trees in certain temperate oak forests (Dickie et al. 2002). Positive feedback with ectomycorrhizae may also be responsible for anomalous low-diversity tropical forests (Connell and Lowman 1989, Torti and Coley 1999). Likewise, soilborne plant pathogens create openings in high latitude coniferous forests, affecting forest composition and successional patterns (Holah et al. 1993, McLaughlin
2001). In temperate forests, host-specific soilborne pathogens cause seedling mortality of black cherry (Prunus serotina) in a distance and density-dependent manner (Packer and Clay 2000). Soilborne pathogens may affect vegetation composition and dynamics in temperate grasslands as well (Mills and Bever 1998, Holah and Alexander 1999, Matthews and Clay 2000, Olff et al. 2000).

However, particular studies of positive or negative feedback in any one habitat may not reflect large-scale geographical (or temporal) patterns of the relative strength of feedback processes. Appropriate empirical tests of the hypothesis illustrated in Fig. 2 could manipulate microbial communities (i.e., the "home vs. away" culture approach of Bever [1994, 1997]) or their presence or absence (i.e., the soil sterilization approach of Van der Putten et al. 1993) across latitudinal and altitudinal (or successional) gradients. Plant-soil feedback, and plant-microbe interactions in general, are likely to interact with other mechanisms, including other biotic interactions that are themselves correlated with spatial or temporal gradients. Nonetheless, the concept of plant-soil microbe interactions as drivers of large-scale vegetation gradients deserves more attention, and has the potential to enrich our understanding of vegetation diversity and succession.

\section{Microbially mediated resource partitioning}

It is difficult to imagine that the diversity of N, P, or other soil nutrient pools changes much over largescale spatial gradients. However, we expect microbially mediated partitioning of soil nutrients to occur most strongly in low productivity habitats, where soil resources are relatively more limiting than light (Tilman 1988) and the benefits of partitioning correspondingly higher. Unproductive habitats can occur anywhere, but the general trend of increasing productivity from poles to equator or high to low altitude leads to the expectation that microbially-mediated resource partitioning will be relatively less important in the tropics or at low altitudes. Empirical tests of this hypothesis are needed.

\section{Conclusions}

Plant interactions with soil microorganisms have become more central to a variety of ecological research efforts, in spite of the fact that most ecologists lack training in microbiology, the techniques of microbial ecology are challenging to apply in the field, and the diversity of microbes and their interactions with plants are to a large extent still unknown. In this paper, we have focused on microbial mediation of niche differentiation in resource use and feedback dynamics between the plant and soil community, but soil microbes may influence many other important ecological processes.

We have posed hypotheses that are consistent with large bodies of existing data, but few studies have been conducted that explicitly test these ideas. With respect 
to microbial mediation of resource differentiation, there is first a need to test the basic premise. Useful approaches range from observational studies of plant nutrient use and microbial associates in greenhouse or field to highly controlled greenhouse and field experiments, where the identity of nutrient resources and the composition of the microbial community are manipulated, and host plant responses are monitored. Advances in molecular and stable isotope techniques make these approaches feasible. Subsequent research might then focus on comparison of the phenomenon in earlyvs. late-successional communities or in communities along latitudinal or altitudinal gradients.

Such comparisons, using techniques of measuring plant growth in sterilized and "cultured" soil, are also needed to evaluate the relative balance of positive and negative feedback over temporal and spatial gradients. These relatively simple techniques have much to offer, although a disadvantage is that the microbial community is treated as a black box and only their net effect on plant growth is revealed. The growing array of molecular techniques will enhance our perspective on plant-soil feedback by allowing the manipulation of individual microbial groups, as well as quantification of microbial populations and their individual effects on plants in diverse natural communities.

\section{ACKNOWLEDGMENTS}

Thanks to the Plant Interactions Group (PIG) at Indiana University's Department of Biology and two anonymous reviewers for helpful feedback. Partial financial support was provided by NSF DEB-0090056 to K. Clay and A. Packer, NSF DEB-0049080 to J. D. Bever, and an Andrew W. Mellon Foundation grant to H. L. Reynolds, J. D. Bever, and P. A. Schultz.

\section{Literature Cited}

Aarssen, L. W. 1984. On the distinction between niche and competitive ability. Acta Biotheoretica 33:67-83.

Aarssen, L. W. 2001. On correlations and causations between productivity and species richness in vegetation: predictions from habitat attributes. Basic and Applied Ecology 2:105114.

Agrios, G. N. 1997. Plant pathology. Academic Press, San Diego, California, USA.

Ahmad, I., and J. A. Hellebust. 1991. Enzymology of nitrogen assimilation in mycorrhiza. Methods in Microbiology 23: $181-202$.

Allen, E. B., and M. F. Allen. 1990. The mediation of competition by mycorrhizae in successional and patchy environments. Pages 367-389 in J. B. Grace and G. D. Tilman, editors. Perspectives on plant competition. Academic Press, New York, New York, USA.

Augspurger, C. K. 1988. Impact of plant pathogens on natural plant populations. Pages 413-433 in A. J. Davy, M. J. Hutchings, and A. R. Watkinson, editors. Plant population ecology. Blackwell Scientific, Oxford, UK.

Augspurger, C. K. 1992. Experimental studies of seedling recruitment from contrasting seed distributions. Ecology 73: $1270-1284$.

Augspurger, C. K., and C. K. Kelly. 1984. Pathogen mortality of tropical tree seedlings: experimental studies of the effects of dispersal distance, seedling density, and light conditions. Oecologia 61:211-217.
Bethlenfalvay, G. J., M. S. Brown, and R. S. Pacovsky. 1982. Relationships between host and endophyte development in mycorrhizal soybean. New Phytologist 90:537-543.

Bever, J. D. 1994. Feedback between plants and their soil communities in an old field community. Ecology 75:19651977.

Bever, J. D. 1999. Dynamics within mutualism and the maintenance of diversity: inference from a model of interguild frequency dependence. Ecology Letters 2:52-61.

Bever, J. D. 2002. Negative feedback within a mutualism: Host-specific growth of mycorrhizal fungi reduces plant benefit. Proceedings of the Royal Society of London 269: 2595-2601.

Bever, J. D., J. B. Morton, J. Antonovics, and P. A. Schultz. 1996. Host-dependent sporulation and species diversity of arbuscular mycorrhizal fungi in a mown grassland. Journal of Ecology 84:71-82.

Bever, J. D., P. Schultz, A. Pringle, and J. Morton. 2001. Arbuscular mycorrhizal fungi: more diverse than meets the eye and the ecological tale of why. BioScience 51:923931.

Bever, J. D., K. M. Westover, and J. Antonovics. 1997. Incorporating the soil community into plant population dynamics: the utility of the feedback approach. Journal of Ecology 85:561-573.

Boerner, R. E. J., B. G. DeMars, and P. N. Leicht. 1996. Spatial patterns of mycorrhizal infectiveness of soils long a successional chronosequence. Mycorrhiza 6:79-90.

Bruehl, G. W. 1987. Soilborne plant pathogens. Cambridge University Press, Cambridge, UK.

Chapin, F. S., III, P. M. Vitousek, and K. van Cleve. 1986. The nature of nutrient limitation in plant communities. American Naturalist 127:48-58.

Chapin, F. S., III, L. R. Walker, C. L. Fastie, and L. C. Sherman. 1994. Mechanisms of primary succession following deglaciation at Glacier Bay, Alaska. Ecological Monographs 64:149-175.

Choler, P., R. Michalet, and R. M. Callaway. 2001. Facilitation and competition on gradients in alpine plant communities. Ecology 82:3295-3308.

Clay, K., and P. Kover. 1996. The Red Queen hypothesis and plant/pathogen interactions. Annual Review of Phytopathology 34:29-50.

Clay, K., and W. H. van der Putten. 1999. Pathogens and plant life histories. Pages 275-302 in T. O. Vuorisalo and P. K. Mutikainen, editors. Life history evolution in plants. Kluwer Academic Publishers, Dordrecht, The Netherlands.

Coley, P. D., J. P. Bryant, and F. S. Chapin III. 1985. Resource availability and plant antiherbivore defense. Science 230: 895-899.

Condit, R., S. P. Hubbell, and R. B. Foster. 1994. Density dependence in two understory tree species in neotropical forest. Ecology 75:671-680.

Connell, J. H. 1971. On the role of natural enemies in preventing competitive exclusion in some marine animals and in rainforest trees. Pages 294-310 in P. J. den Boer and G. R. Gradwell, editors. Dynamics of populations. Center for Agricultural Publishing and Documentation, Wageningen, The Netherlands.

Connell, J. H., and M. D. Lowman. 1989. Low-diversity tropical rainforests: some possible mechanisms for their existence. American Naturalist 134:88-119.

Connell, J. H., and R. O. Slatyer. 1977. Mechanisms of succession in natural communities and their role in community stability and organization. American Naturalist 111:11191144.

Crocker, R. L., and J. Major. 1955. Soil development in relation to vegetation and surface age at Glacier Bay, Alaska. Journal of Ecology 43:427-448. 
Dickie, I. A., R. T. Koide, and K. C. Steiner. 2002. Influences of established trees on mycorrhizas, nutrition, and growth of Quercus rubra seedlings. Ecological Monographs 72: $505-521$.

Elton, C. S. 1958. The ecology of invasions by plants and animals. Methuen, London, UK.

Eom, A. H., D. C. Hartnett, and G. W. T. Wilson. 2000. Host plant species effects on arbuscular mycorrhizal fungal communities in tallgrass prairie. Oecologia 122:435-444.

Fox, J. F. 1977. Alternation and coexistence of tree species. American Naturalist 111:69-89.

Ghiselin, M. T. 1974. The economy of nature and the evolution of sex. University of California Press, Berkeley, California, USA.

Givnish, T. J. 1999. On the causes of gradients in tropical tree diversity. Journal of Ecology 87:193-210.

Glesener, R. R., and D. Tilman. 1978. Sexuality and the components of environmental uncertainty: clues from geographical parthenogenesis in terrestrial animals. American Naturalist 112:659-673.

Gorham, E., P. M. Vitousek, and W. A. Reiners. 1979. The regulation of chemical budgets over the course of terrestrial ecosystem succession. Annual Review of Ecological Systems 10:53-84.

Grayston, S. J., S. Wang, C. D. Campbell, and A. C. Edwards. 1998. Selective influence of plant species on microbial diversity in the rhizosphere. Soil Biology and Biochemistry 30:369-378.

Greenlee, J. T., and R. M. Callaway. 1996. Abiotic stress and the relative importance of interference and facilitation in montane bunchgrass communities in western Montana. American Naturalist 148:386-396.

Gutschick, V. P. 1981. Evolved strategies in nitrogen acquisition by plants. American Naturalist 118:607-637.

Hamilton, E. W., III, and D. A. Frank. 2001. Can plants stimulate soil microbes and their own nutrient supply? Evidence from a grazing tolerant grass. Ecology 82:23972402.

Harms, K. E., S. J. Wright, O. Calderon, A. Hernandez, and E. A. Herre. 2000. Pervasive density-dependent recruitment enhances seedling diversity in a tropical forest. Nature 404:493-495.

Harte, J., and A. P. Kinzig. 1993. Mutualism and competition between plants and decomposers: implications for nutrient allocation in ecosystems. American Naturalist 141:829846.

Hawkins, H. J., A. Johansen, and E. George. 2000. Uptake and transport of organic and inorganic nitrogen by arbuscular mycorrhizal fungi. Plant and Soil 226:275-285.

HilleRisLambers, J., J. S. Clark, and B. Beckage. 2002. Density-dependent mortality and the latitudinal gradient in species diversity. Nature 417:732-735.

Hodge, A., C. D. Campbell, and A. H. Fitter. 2001. An arbuscular mycorrhizal fungus accelerates decomposition and acquires nitrogen directly from organic material. Nature 413:297-299.

Hodge, A., D. Robinson, and A. Fitter. 2000a. Are microorganisms more effective than plants at competing for nitrogen? Trends in Plant Science 5:304-308.

Hodge, A., D. Robinson, and A. H. Fitter. 2000b. An arbuscular mycorrhizal inoculum enhances root proliferation in, but not nitrogen capture from, nutrient-rich patches in soil. New Phytologist 145:575-584.

Holah, J. C., and H. M. Alexander. 1999. Soil pathogenic fungi have the potential to affect co-existence of two tallgrass prairie species. Journal of Ecology 84:598-608.

Holah, J. C., M. V. Wilson, and E. M. Hansen. 1993. Effects of a native forest pathogen, Phellinus weirii, on Douglasfir forest composition in western Oregon. Canadian Journal of Forestry Research 23:2473-2480.
Janos, D. P. 1980. Mycorrhizae influence tropical succession. Mycorrhizae 12:56-64.

Janzen, D. H. 1970. Herbivores and the number of tree species in tropical forests. American Naturalist 102:592-595.

Jayachandran, K., A. P. Schwab, and B. A. D. Hetrick. 1992. Mineralization of organic phosphorus by vesicular-arbuscular mycorrhizal fungi. Soil Biology and Biochemistry 24: 897-903.

Katan, J. 1991. Interactions of roots with soil-borne pathogens. Pages 823-836 in Y. Waisel, A. Eshel, and U. Kafkafi, editors. Plant roots: the hidden half. Marcel Dekker, New York, New York, USA.

Knops, J. M. H., D. Tilman, N. M. Haddad, S. Naeem, C. E. Mitchell, J. Haarstad, M. E. Ritchie, K. M. Howe, P. B. Reich, E. Siemann, and J. Groth. 1999. Effects of plant species richness on invasion dynamics, disease outbreaks, insect abundances and diversity. Ecology Letters 2:286293.

Larson, J. L., and E. Siemann. 1998. Legumes may be symbiont-limited during old-field succession. American Midland Naturalist 140:90-95.

Lavelle, P., and A. V. Spain. 2001. Soil ecology. Kluwer Academic, Boston, Massachusetts, USA.

Leath, S., A. L. Scharen, and M. E. Dietz-Holmes. 1993. Factors associated with global occurrences of Septoria nodorum blotch and Septoria tritici blotch of wheat. Plant Disease 77:1266-1270.

Levin, D. A. 1975. Pest pressure and recombination systems in plants. American Naturalist 109:437-451.

Marschner, H. 1995. Mineral nutrition of higher plants. Academic Press, San Diego, California, USA.

Matthews, J., and K. Clay. 2000. Influence of fungal endophyte infection on plant-soil feedback and community interactions. Ecology 82:500-509.

McKane, R. B., L. C. Johnson, G. R. Shaver, K. J. Nadelhoffer, E. B. Rastetter, B. Fry, A. E. Giblin, K. Kielland, B. L. Kwiatkowski, J. A. Laundre, and G. Murray. 2002. Resource-based niches provide a basis for plant species diversity and dominance in arctic tundra. Nature 415:6871.

McLaughlin, J. A. 2001. Impact of Armillaria root disease on succession in red pine plantations in southern Ontario. The Forestry Chronicle 77:519-524.

Medve, R. J. 1984. The mycorrhizae of pioneer species in disturbed ecosystems in western Pennsylvania. American Journal of Botany 71:787-794.

Michelsen, A., I. K. Schmidt, S. Jonasson, C. Quarmby, and D. Sleep. 1996. Leaf $15 \mathrm{~N}$ abundance of subarctic plants provides field evidence that ericoid, ectomycorrhizal and non- and arbuscular mycorrhizal species access different sources of soil nitrogen. Oecologia 105:53-63.

Miller, A. E., and W. D. Bowman. 2002. Variation in nitrogen-15 natural abundance and nitrogen uptake traits among co-occurring alpine species: do species partition nitrogen by form? Oecologia 130:609-616.

Mills, K. E., and J. D. Bever. 1998. Maintenance of diversity within plant communities: soil pathogens as agents of negative feedback. Ecology 79:1595-1601.

Mittelbach, G. G., C. F. Steiner, S. M. Scheiner, K. L. Gross, H. L. Reynolds, R. B. Waide, M. R. Willig, S. I. Dodson, and L. Gough. 2001. What is the observed relationship between species richness and productivity. Ecology 82: 2381-2396.

Molofsky, J., J. D. Bever, and J. Antonovics. 2001. Coexistence under positive frequency dependence. Proceedings of the Royal Society of London 268:273-277.

Molofsky, J., J. D. Bever, J. Antonovics, and T. J. Newman. 2002. Negative frequency-dependence and the importance of spatial scale. Ecology 83:21-27. 
Olff, H., B. Hoorens, R. G. M. de Goede, W. H. van der Putten, and J. M. Gleichman. 2000. Small-scale shifting mosaics of two dominant grassland species: the possible role of soil-borne pathogens. Oecologia 125:45-54.

Packer, A., and K. Clay. 2000. Soil pathogens and spatial patterns of seedling mortality in a temperate tree. Nature 404:278-281.

Paul, E. A., and F. E. Clark. 1996. Soil microbiology and biochemistry. Academic Press, San Diego, California, USA.

Poorter, H. 1990. Interspecific variation in relative growth rate: on ecological causes and physiological consequences. Pages 45-68 in H. Lambers, M. L. Cambridge, H. Konings, and T. L. Pons, editors. Causes and consequences of variation in growth rate and productivity of higher plants. SPB Academic Publishing, The Hague, The Netherlands.

Read, D. J. 1991. Mycorrhizas in ecosystems. Experientia 47:376-391.

Read, D. J. 1993. Mycorrhiza in plant communities. Advances in Plant Pathology 9:1-31.

Rejmanek, M., and D. M. Richardson. 1996. What attributes make some plant species more invasive? Ecology 77:16551661.

Reynolds, H. L. 1999. Plant interactions: competition. Pages 649-675 in F. I. Pugnaire and F. Valladares, editors. Handbook of functional plant ecology. Marcel Dekker, New York, New York, USA.

Richardson, D. M., N. Allsopp, C. M. D’Antonio, S. J. Milton, and M. Rejmanek. 2000. Plant invasions- the role of mutualisms. Biological Reviews of the Cambridge Philosophical Society 75:65-93.

Rosenzweig, M. L. 1995. Species diversity in space and time. Cambridge University Press, New York, New York, USA.

Rovira, A. D. 1969. Plant root exudates. Botanical Review 35:35-56.

Sanders, H. L. 1968. Marine benthic diversity: a comparative study. American Naturalist 102:243-282.

Schlesinger, W. H. 1991. Biogeochemistry: an analysis of global change. Academic Press, San Diego, California, USA.

Smith, S. E., and D. J. Read. 1997. Mycorrhizal symbiosis. Academic Press, London, UK.

Sprent, J. I. 1993. The role of nitrogen fixation in primary succession. Pages 209-220 in J. Miles and D. W. H. Walton, editors. Primary succession on land. Blackwell Scientific Publications, Boston, Massachusetts, USA.

Tabatabai, T., and W. A. Dick. 2002. Enzymes in soil. Pages 567-596 in R. G. Burns and R. P. Dick, editors. Enzymes in the environment. Marcel Dekker, New York, New York, USA.

Tarafdar, J. C., and H. Marschner. 1994. Phosphatase activity in the rhizosphere and hyphosphere of VA mycorrhizal wheat supplied with inorganic and organic phosphorus. Soil Biology and Biochemistry 26:387-395.

Tate, R. L., III. 1997. Soil microbial diversity: whither to now? Soil Science 162:605-606.

Thompson, J. N., et al. 2001. Frontiers of ecology. BioScience 51:15-24.

Tilman, D. 1988. Plant strategies and the dynamics and structure of plant communities. Princeton University Press, Princeton, New Jersey, USA.

Tilman, D., and S. Pacala. 1993. The maintenance of species richness in plant communities. Pages 13-25 in R. E. Ricklefs and D. Schluter, editors. Species diversity in ecological communities: historical and geographical perspectives. University of Chicago Press, Chicago, Illinois, USA.

Torsvik, V., J. Goksøyr, and F. L. Daae. 1990. High diversity in DNA of soil bacteria. Applied Environmental Microbiology 56:782-787.

Torsvik, V., J. Goksøyr, F. L. Daae, R. Sørheim, J. Michelsen, and K. Salte. 1994. Use of DNA analysis to determine the diversity of microbial communities. Pages 39-48 in K. Ritz, J. Dighton, and K. E. Giller, editors. Beyond the biomass: compositional and functional analysis of soil microbial communities. Wiley, Chichester, UK.

Torti, S. D., and P. D. Coley. 1999. Tropical monodominance: a preliminary test of the ectomycorrhizal hypothesis. Biotropica 31:220-228.

Tresner, H. D., M. P. Backus, and J. T. Curtis. 1954. Soil microfungi in relation to the hardwood forest continuum in Southern Wisconsin. Mycologia 46:313-333.

Turnbull, M. H., R. Goodall, and G. R. Stewart. 1995. The impact of mycorrhizal colonization upon nitrogen source utilization and metabolism in seedlings of Eucalyptus grandis Hill ex Maiden and Eucalyptus maculata Hook. Plant, Cell and Environment 18:1386-1394.

Turnbull, M. H., S. Schmidt, P. D. Erskine, S. Richards, and G. R. Stewart. 1996. Root adaptation and nitrogen source acquisition in natural ecosystems. Tree Physiology 16:941948 .

Van der Heijden, M. G. A., J. N. Klironomos, M. Ursic, P. Moutoglis, R. Streitwolf-Engel, T. Boller, A. Wiemken, and I. R. Sanders. 1998. Mycorrhizal fungal diversity determines plant biodiversity, ecosystem variability and productivity. Nature 396:69-72.

Van der Putten, W. H., P. H. T. Maas, W. J. M. Van Gulik, and H. Brinkman. 1990. Characterization of soil organisms involved in the degeneration of Ammophila arenaria. Soil Biology and Biochemistry 22:845-852.

Van der Putten, W. H., and S. R. Troelstra. 1990. Harmful soil organisms in coastal foredunes involved in degeneration of Ammophila arenaria and Calammophila baltica. Canadian Journal of Botany 68:1560-1568.

Van der Putten, W. H., C. Van Dijk, and B. A. M. Peters. 1993. Plant-specific soil-borne diseases contribute to succession in foredune vegetation. Nature 362:53-56.

Waide, R. B., M. R. Willig, C. F. Steiner, G. Mittelbach, L. Gough, S. I. Dodson, G. P. Juday, and R. Parmenter. 1999. The relationship between productivity and species richness. Annual Review of Ecological Systematics 30:257-300.

Walker, T. W., and J. K. Syers. 1976. The fate of P during pedogenesis. Geoderma 15:1-19.

Weltzien, H. C. 1972. Geophytopathology. Annual Review of Phytopathology 10:277-298.

Westover, K. M., and J. D. Bever. 2001. Mechanisms of plant species coexistence: complementary roles of rhizosphere bacteria and root fungal pathogens. Ecology 82:3285-3294.

Wills, C., R. Condit, R. B. Foster, and S. P. Hubbell. 1997. Strong density- and diversity- related effects help to maintain tree species diversity. Proceedings of the National Academy of Sciences (USA) 94:1252-1257.

Wohlrab, G., R. W. Tuveson, and C. E. Olmsted. 1963. Fungal populations from early stages of succession in Indiana dune sand. Ecology 44:734-740.

Woods, K. D. 1979. Reciprocal replacement and the maintenance of codominance in a beech maple forest. Oikos $\mathbf{3 3}$ : 31-39.

Yang, X. B., and F. Feng. 2001. Ranges and diversity of soybean fungal diseases in North America. Phytopathology 91:769-775.

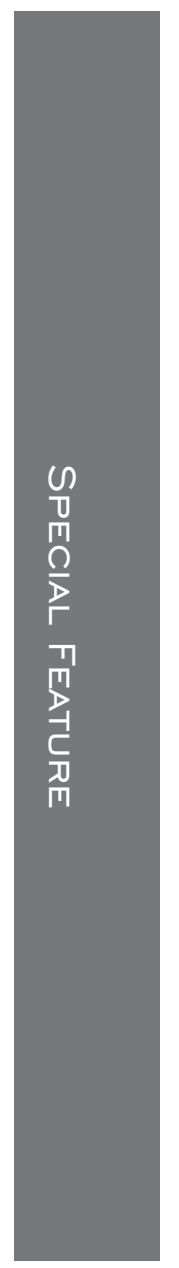

